\title{
Left ventricular volumes during ventricular tachycardia, first post-tachycardia beat, and subsequent beats in normal rhythm
}

\author{
David Hunt, ${ }^{1}$ John A. Burdeshaw, and William A. Baxley \\ From the Division of Cardiology, Department of Medicine, University of Alabama Medical Center, Birmingham, \\ Alabama, U.S.A.
}

Twenty-eight adults undergoing diagnostic cardiac catheterization had left ventricular volumes measured by quantitative biplane angiocardiography during transient ventricular tachycardia induced by the injection of contrast material. Left ventricular end-diastolic volume was significantly less during tachycardia compared to subsequent normal rhythm, suggesting decreased ventricular filling as a contributing cause of low effective cardiac output during ventricular tachycardia. End-systolic volumes were also significantly less during the tachycardia. Ejection fraction was lower during tachycardia, possibly due to an acute decreased volume load on the left ventricle from the inadequate filling. The end-diastolic volume of the first normal beat following the tachycardia was not significantly different from that during normal rhythm, but there was an augmented contraction, with increased ejection fraction and lowered end-systolic volume compared with the first normal beat.

Ventricular tachycardia occurs with a variety of cardiac diseases, and may result in severe haemodynamic deterioration manifested by anginal pain, heart failure, cardiogenic shock, or death (Friedberg, 1966). In spite of the obvious importance of such arrhythmias, little information has been published on the accompanying haemodynamic alterations (Nakano, 1964; Benchimol et al., 1965; McIntosh and Morris, 1966; Pavek, Drimal, and Selecky, 1967; Benchimol et al., 1969) because of the short duration of the arrhythmias and their often lifethreatening nature (McIntosh and Morris, 1966). Measurements have shown that ventricular tachycardia causes a reduction in cardiac output and stroke volume (Nakano, 1964; Benchimol et al., 1965; McIntosh and Morris, I966) and peak aortic flow rates in man (Benchimol et al., 1969) and a reduction in heart size in dogs (Katz, I955; Bristow et al., 1963; Rushmer, 1970). Methods are available for determining left ventricular volumes in man from biplane ventricular angiograms (Dodge et al., 1966). Furthermore, such left ventriculography is frequently accompanied by an initial burst of ventricular tachycardia due to injection of contrast material near the endocardium. This is usually

Received 28 August 1973.

1 Present address: Cardiac Department, Royal Melbourne Hospital, Parkville, Victoria 3050, Australia. followed by normal rhythm, thus providing the opportunity to define quantitatively some of the changes associated with ventricular tachycardia as compared to normal rhythm in the same patient.

In addition, the characteristics of the first beat in normal rhythm following either an isolated premature ventricular beat or a run of ventricular tachycardia have been the subject of many reports. The enhanced contractility of such beats is related to the prematurity of the ventricular contractions rather than to changes in diastolic fibre length (Hoffman, Bindler, and Suckling, 1956; Siebens et al., 1959; Lendrum et al., 1960; Meijler et al., 1962). The occurrence of ventricular tachycardia during angiography has allowed us to study the post-tachycardia beat in the intact human heart.

Accordingly this report describes the alterations in ventricular volumes associated with ventricular tachycardia and the first succeeding beat in normal rhythm in a series of patients with heart disease studied by quantitative biplane angiography.

\section{Subjects and methods}

The records of all adult patients at the University of Alabama Medical Center and the Birmingham Veterans Administration Hospital who underwent diagnostic cardiac catheterization and quantitative biplane left 
ventriculography were reviewed. Twenty-eight met the following criteria.

(I) Ventricular tachycardia for four or more beats occurred in association with the injection of the contrast material, followed by a return to sinus rhythm.

(2) The quality of the films was adequate to allow measurement of ventricular volumes over four or more cycles of the tachycardia. Diagnoses included chronic rheumatic heart disease (I9 patients), congenital heart disease (3 patients), coronary artery disease (3 patients), primary myocardial disease (I patient), and normal (2 patients). Right and left heart catheterization was performed in the $\mathbf{2 8}$ patients and coronary arteriography in the 3 patients with coronary artery disease. Biplane left ventriculography was performed using a Schonander film changer and an injection of $75 \mathrm{ml} 76$ per cent Renografin into the left ventricle over 2 to $2 \frac{1}{2}$ seconds. In 13 patients, films were made at 12 a second for 2 seconds and then 6 a second for 3 to 4 seconds, and in the remaining 15 patients at 6 a second for 5 to 6 seconds. The timing of the film exposures and the simultaneous electrocardiogram were recorded on a multichannel recorder. The ventricular rates during the ventricular tachycardia and during the subsequent normal rhythm as well as the length of the pause between the last beat of the ventricular tachycardia and the first normal beat were measured. Left ventricular chamber volumes were calculated from the films by the method of Dodge et al. (1966), which assumes an ellipsoid reference figure for the ventricular cavity with corrections for non-parallel $x$-ray beams. The calculated volumes during ventricular tachycardia were corrected for body surface area and plotted first against the time after the first QRS complex to form a continuous curve over several cycles, and then against time after onset of each preceding QRS to form a composite curve over a single theoretical cycle. End-diastolic volume (EDV) and end-systolic volume (ESV) were recorded as maximum and minimum volumes on the curves. The ejection fraction (EF) was determined by the formula:

$$
\mathrm{EF}=\frac{\mathrm{EDV}-\mathrm{ESV}}{\mathrm{EDV}}
$$

In a similar manner, the ventricular volumes of the first normal beat following the ventricular tachycardia were calculated in the 13 patients with 12 per second filming. Volumes during normal rhythm were the average of at least 2 cycles and were determined in 16 patients. In 13 patients volumes during each phase of the sequence were determined. The significance of changes in the volumes and ejection fractions was assessed by the Wilcoxon matched-pairs signed-ranks test. This is a nonparametric alternative to the t-test for two samples where there is natural pairing of the observations such as measurements on a subject before and after treatment. The main advantage in using the Wilcoxon test is that no particular probability distribution of the data is assumed, whereas the t-test assumes that the data are normally distributed.

In those patients in whom no mitral regurgitation was seen on the angiogram during normal sinus rhythm, the films were carefully examined for such regurgitation during the tachycardia.

\section{Results}

The initial rate of the ventricular tachycardia varied from 120 to 280 beats a minute. Rates were between 151 and 180 in 16 patients, less than 141 in 7 patients, and above 181 in 5 patients. There was little beat-to-beat variation in the rate of the tachycardia in 27 of the patients, and the volumes during the arrhythmia in these patients showed good reproducibility over successive cardiac cycles (Fig. I).

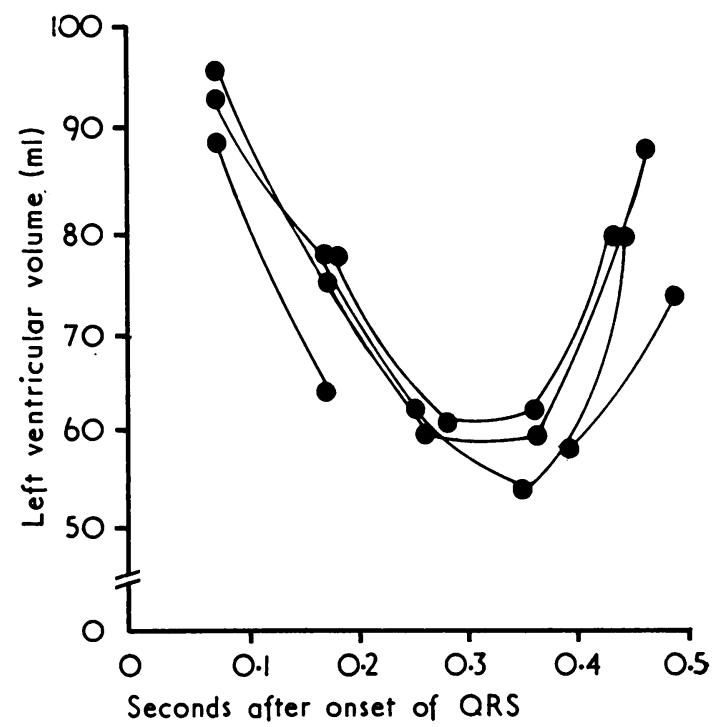

FIG. I The reproducibility of ventricular volumes over successive cycles during ventricular tachycardia is seen.

In one patient, however, in whom films were made at 12 a second, the rate of ventricular tachycardia slowed from 167 to 145 to 97 a minute over three successive beats. In each cycle a point close to end-diastole was obtained (Fig. 2) and it can be seen that though the end-systolic volume remained relatively constant, the end-diastolic volume increased conspicuously with decreasing rate.

Fig. 3 shows the changes in end-diastolic and endsystolic volumes and ejection fractions between ventricular tachycardia and normal rhythm in 16 patients. The end-diastolic volume during the tachycardia (range $40-350$, mean $185 \mathrm{ml} / \mathrm{m}^{2}$ ) was significantly less $(\mathrm{P}<0.001)$ than in normal rhythm (85-415, mean $\left.246 \mathrm{ml} / \mathrm{m}^{2}\right)$. The end-systolic volume during the tachycardia (20 to 310 , mean II $\left.\mathrm{ml} / \mathrm{m}^{2}\right)$ was also significantly less $(P<0.05)$ than in normal rhythm ( 35 to 330 , mean $14 \mathrm{I} \mathrm{ml} / \mathrm{m}^{2}$ ), 


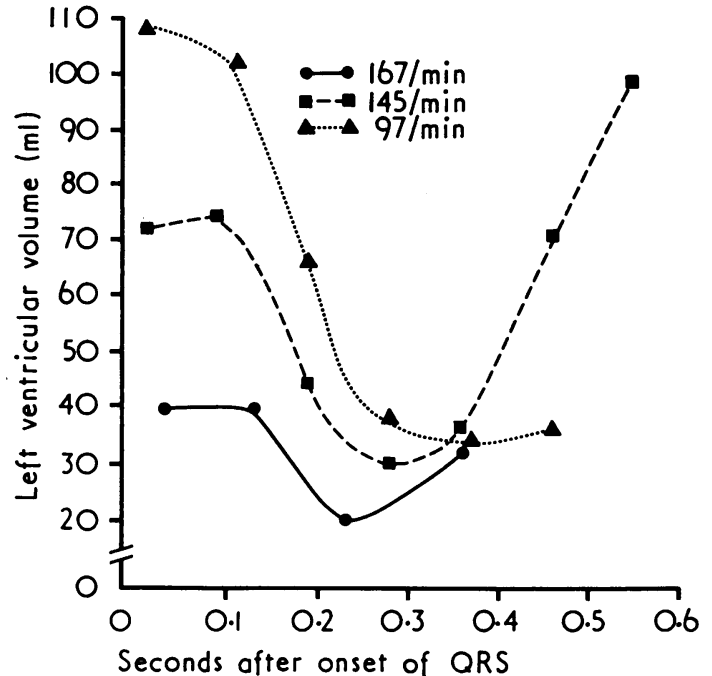

FIG. 2 The end-diastolic volume increased with slowing of the heart rate during ventricular tachycardia while the end-diastolic volume remained relatively constant.

and the ejection fraction during tachycardia (O.II to 0.72 , mean 0.39 ) was significantly less $(P<0.01)$ than in normal rhythm (0.17 to 0.65 , mean 0.47$)$.

Fig. 4 shows the changes in the 13 patients in whom volume measurements were made during both the first normal beat and subsequent normal rhythm. The end-diastolic volume of the first normal beat (135 to 415 , mean $260 \mathrm{ml} / \mathrm{m}^{2}$ ) was not significantly different $(P>0.05)$ from the normal rhythm ( 85 to 415 , mean $256 \mathrm{ml} / \mathrm{m}^{2}$ ). The endsystolic volume of the first normal beat ( 20 to 280 , mean $\left.120 \mathrm{ml} / \mathrm{m}^{2}\right)$ was significantly less $(P<0.00 \mathrm{I})$ than the normal rhythm ( 35 to 330 , mean $145 \mathrm{ml} / \mathrm{m}^{2}$ ). The ejection fraction of the first normal beat $(0.23$ to 0.86 , mean 0.57$)$ was significantly greater $(P<0.005)$ than in normal rhythm (0.17 to 0.65 , mean 0.46 ). The ranges and means of the values during normal rhythm are slightly different in Fig. 3 and 4: this is because there were 16 patients in the former and only 13 in the latter. The results of these statistical tests are shown in summary in Fig. 5.

Among all patients combined, there was no correlation between the degree of reduction of enddiastolic volume during the arrhythmia and the rate of the tachycardia $(r=-0.088, P>0.10)$ or between the end-diastolic volume of the first normal beat and the duration of the post-tachycardia pause $(P>0 \cdot 10)$.

Of the 28 patients, 12 showed no angiographic evidence of mitral regurgitation during normal rhythm, and, of these, 4 showed angiographic evidence of mild to moderate mitral regurgitation limited to the duration of the tachycardia.

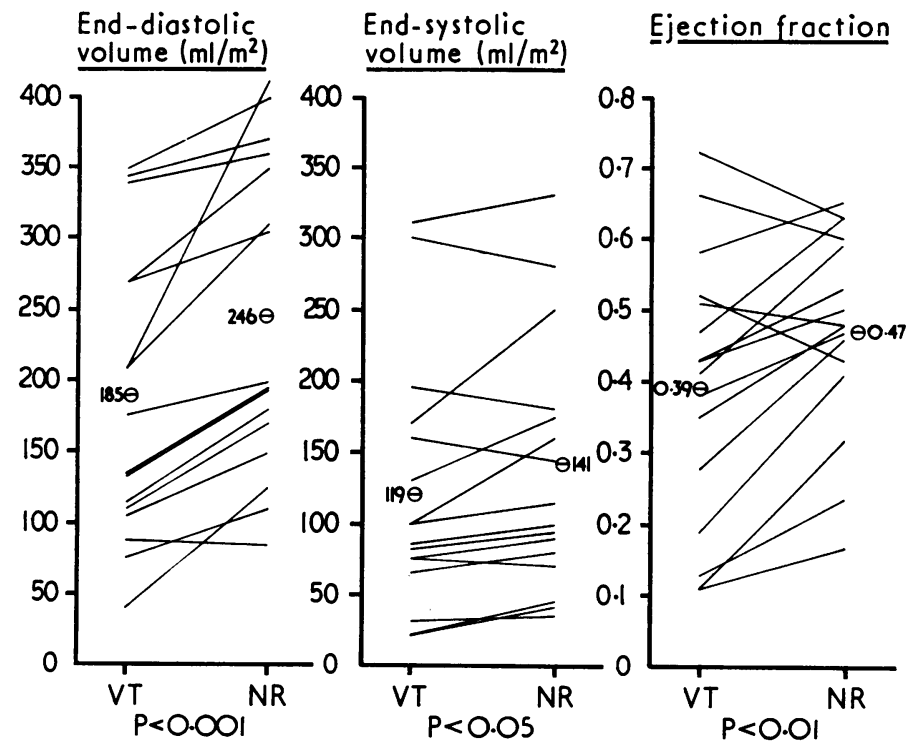

FIG. 3 End-diastolic and end-systolic volumes and ejection fraction during ventricular tachycardia and normal rhythm are shown. Statistical differences were analysed by the Wilcoxon matched-pairs signed-ranks test. 


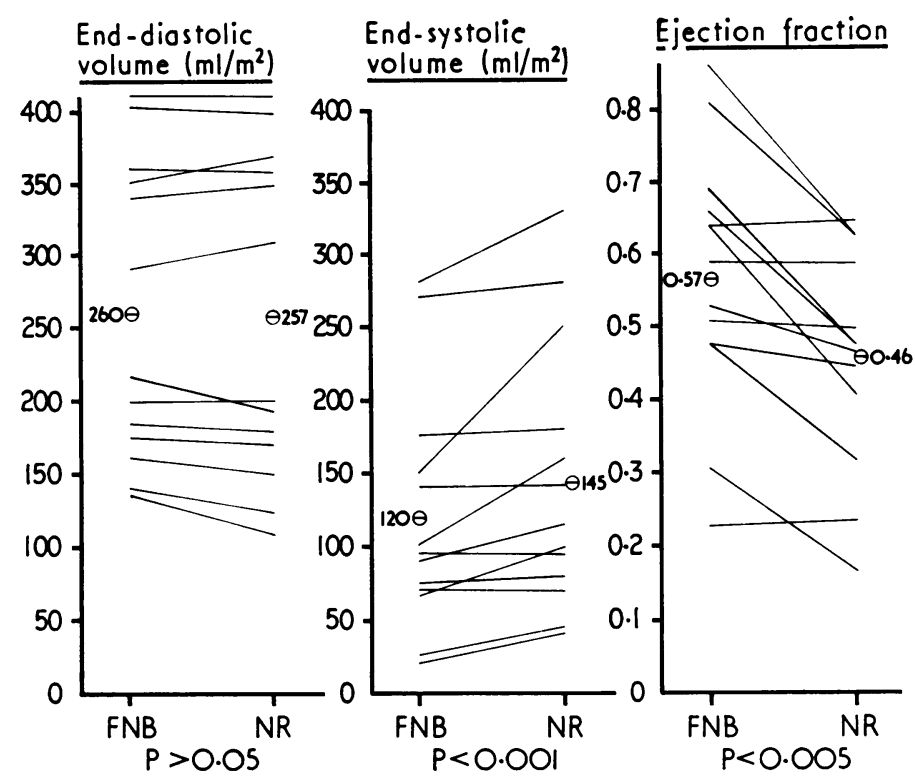

FIG. 4 End-diastolic and end-systolic volumes and ejection fraction during the first normal beat and subsequent normal rhythm are shown. Statistical differences were analysed by the Wilcoxon test.

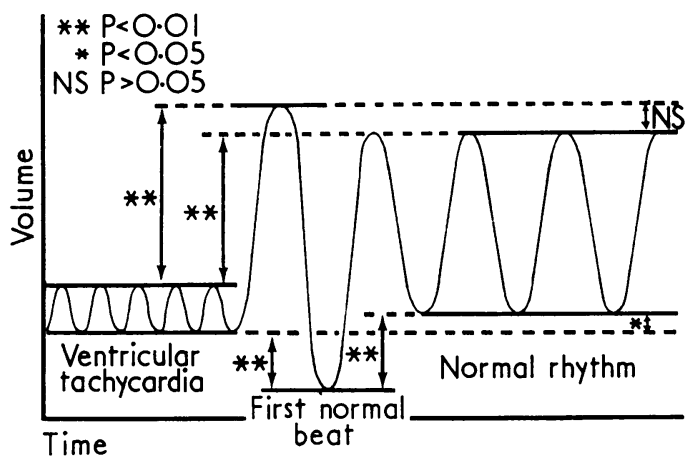

FIG. 5 Schematic representation of the ventricular volumes during ventricular tachycardia, the first normal beat, and subsequent normal rhythm.

\section{Discussion}

This study shows that ventricular tachycardia induced during left ventricular angiography is associated with a reduction in end-diastolic volume, with lesser reductions in ejection fraction and endsystolic volume compared to the patient's usual rhythm. These changes, however, occurring during short runs of induced ventricular tachycardia may differ from those during spontaneous or sustained arrhythmias.
The reduction in end-diastolic volume during the tachycardia is due to reduced ventricular filling because of a shortened diastolic filling period (Katz, 1955; Nakano, 1964; Brecher and Galletti, 1965; McIntosh and Morris, 1966; Pavek et al., 1967; Benchimol et al., 1969). The reduction of enddiastolic volume was related to the ventricular rate in the one patient in whom the ventricular rate varied. For the total patient group, however, no such relation could be found, probably because of the heterogeneity of our patient population and other factors such as altered ventricular compliance, and myocardial and valvular disease (Friedberg, 1966; McIntosh and Morris, 1966; Benchimol et al., 1969).

In human beings, stroke volume and cardiac output often fall during spontaneous or induced ventricular tachycardia at rates over I2O a minute (Benchimol et al., 1965). The changes with pacinginduced ventricular tachycardia were similar to, but more pronounced than those of induced atrial tachycardia at the same rate (Benchimol et al., 1965) and may be due to desynchronization of the ventricular contraction, loss of the preceding atrial boost, or to the development of mitral regurgitation. Certainly, mitral regurgitation limited to the duration of the tachycardia occurred in a third of our patients without pre-existing regurgitation, but was only of a mild to moderate degree and was 
similar to that occurring with isolated premature ventricular contractions (Sellers et al., 1964).

The finding that an increased stroke volume occurred with the first normal beat following the ventricular tachycardia from an end-diastolic volume not significantly different from that during normal rhythm is of interest, as subjective impressions from the angiogram often suggest this volume is larger than usual. Similar findings have been previously reported in a postextrasystolic beat (Rackley, Whalen, and McIntosh, 1966). The length of the post-tachycardia pause resulted in a number of films being made at or near end-diastole, thus allowing a more accurate assessment of the enddiastolic volume of the first normal beat than would have been possible with other single beats.

It used to be considered that the potentiation of contraction of the first beat following either an isolated premature ventricular beat or a run of induced tachycardia resulted from an increased diastolic volume and the Frank-Starling mechanism (Wiggers, 1952). Even though our data indicate that this potentiation occurs from an unchanged end-diastolic volume, the Frank Starling mechanism could still play some part, as at enddiastole the left ventricular compliance curve is such that small, poorly measurable increases in volume may cause large increases in end-diastolic tension and significant stroke volume (Dodge, Hay, and Sandler, 1962).

As already stated, the phenomenon of postextrasystolic or post-stimulation potentiation is well known (Wiggers, 1952; Rosin and Farah, 1955; Meijler et al., 1962) and has been shown again in this study. Calculation of the increased contractility of this postectopic beat depended on our demonstration of a reduced end-systolic volume as the enddiastolic volume was unaltered. This reduction in end-systolic volume was shown even though the measurement was assessed from only one frame in each patient and thus may represent a slightly higher value than the true end-systolic volume. The potentiation thus appears to be due to an increase in muscle contractility. Studies in isolated muscle preparations (Hoffman et al., 1956; Blinks and Koch-Weser, 196I), in the intact mammalian ventricle (Siebens et al., 1959; Lendrum et al., 1960; Meijler et al., 1962) and in intact human beings using ultrasonic flowmeters (Benchimol et al., 1969), have all shown that the potentiation is not primarily related to the changes in the diastolic fibre length, or to the duration of the subsequent compensatory pause, but rather to the degree of prematurity of the premature ventricular contractions. A further augmentation of the post-tachycardia beat might come from the reductions in after- load with the fall in arterial blood pressure following the tachycardia (Tsakiris et al., 1968).

\section{References}

Benchimol, A., Ellis, J. G., Diamond, E. C., and Wu, T. (1965). Hemodynamic consequences of atrial and ventricular arrhythmias in man. American Heart fournal, 70, 775.

Benchimol, A., Stegall, H. F., Maroko, P. R., Gartlan, J. L., and Brener, L. (1969). Aortic flow velocity in man during cardiac arrhythmias measured with the Doppler catheterflowmeter system. American Heart fournal, 78, 649.

Blinks, J. R., and Koch-Weser, J. (196I). Analysis of the effects of changes in rate and rhythm upon myocardial contractility. Fournal of Pharmacology and Experimental Therapeutics, 134, 373.

Brecher, G. A., and Galletti, P. M. (1965). Functional anatomy of cardiac pumping. In Handbook of Physiology, Section 2, Circulation, Vol. 2, p. 775. Ed. by W. F. Hamilton and P. Dow. American Physiological Society, Washington, D.C.

Bristow, J. D., Ferguson, R. E., Mintz, F., and Rapaport, E. (1963). The influence of heart rate on left ventricular volume in dogs. Fournal of Clinical Investigation, 42, 649.

Dodge, H. T., Hay, R. E., and Sandler, H. (1962). Pressurevolume characteristics of the diastolic left ventricle of man with heart disease. American Heart fournal, 64, 503.

Dodge, H. T., Sandler, H., Baxley, W. A., and Hawley, R. R. (1966). Usefulness and limitations of radiographic methods for determining left ventricular volume. American fournal of Cardiology, 18, 10.

Friedberg, C. K. (1966). The ectopic tachycardias. In Diseases of the Heart, 3rd ed., p. 562. W. B. Saunders, Philadelphia and London.

Hoffman, B. F., Bindler, E., and Suckling, E. E. (1956). Postextrasystolic potentiation of contraction in cardiac muscle. American fournal of Physiology, 105, 95.

Katz, L. N. (1955). Analysis of the several factors regulating the performance of the heart. Physiological Reviews, 35, 91.

Lendrum, B., Feinberg, H., Boyd, E., and Katz, L. N. (I960). Rhythm effects of contractility of the beating isovolumic left ventricle. American fournal of Physiology, 199, I 115.

McIntosh, H. D., and Morris, J. J., Jr. (I966). The hemodynamic consequences of arrhythmias. Progress in Cardiovascular Diseases, 8, 330.

Meijler, F. L., Bogaard, F. V. D., Tweel, H. V. D., and Durrer, D. (1962). Postextrasystolic potentiation in the isolated rat heart. American fournal of Physiology, 202, 631.

Nakano, J. (1964). Effects of atrial and ventricular tachycardias on the cardiovascular dynamics. American fournal of Physiology, 206, 547.

Pavek, K., Drimal, J., and Selecky, F. V. (1967). Circulatory effects of disodium edetate in digoxin-induced ventricular tachycardia. Cardiologia, 50, 297.

Rackley, C. E., Whalen, R. C., and McIntosh, H. D. (1966). Ventricular volume studies in a patient with hypertrophic subaortic stenosis. Circulation, 34, 579.

Rosin, H., and Farah, A. (1955). Post-stimulation potentiation of contractility in the isolated auricle of the rabbit. American fournal of Physiology, 180, 75.

Rushmer, R. F. (1970). Cardiovascular Dynamics, 3rd ed., p. 74. W. B. Saunders, Philadelphia and London.

Sellers, R. D., Levy, M. J., Amplatz, K., and Lillehei, C. W. (1964). Left retrograde cardioangiography in acquired cardiac disease. Technic, indications and interpretations in 700 cases. American fournal of Cardiology, $14,437$.

Siebens, A. A., Hoffman, B. F., Cranefield, P. F., and Brooks, C. M. (1959). Regulation of contractile force during 
ventricular arrhythmias. American fournal of Physiology, I97, 97 I.

Tsakiris, A. G., Vandenberg, R. A., Banchero, N., Sturm, R. E., and Wood, E. H. (1968). Variations in left ventricular end-diastolic pressure, volume, and ejection fraction with changes in outflow resistance in anesthetized intact dogs. Circulation Research, 23, 213.
Wiggers, C. J. (1952). Circulatory Dynamics: Physiologic Studies, p. 79. Grune and Stratton, New York.

Requests for reprints to Dr. David Hunt, Cardiac Department, Royal Melbourne Hospital, Parkville 3050, Australia. 